\title{
LOWERING AND PHASE SHIFTING OF TEMPERATURE PROFILES WITH PHASE CHANGE MATERIALS IN MINERGIETM HOUSES
}

\author{
C. MURISET ${ }^{(\text {a) }}$, P. W. EGOLF ${ }^{(a)}$, D. VUARNOZ ${ }^{(a)}$, P. HAAS $^{(b)}$

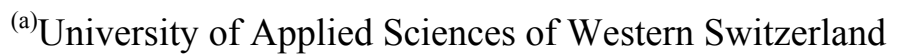 \\ Haute Ecole d'Ingénerie et de Gestion du Canton de Vaud \\ Institute of Thermal Sciences and Engineering \\ CH 1400 Yverdon-les-Bains, Switzerland \\ Corresponding author: mail: Peter.egolf@,heig-vd.ch; Tel.: 0041245576157 \\ (a)University of Applied Sciences of Western Switzerland \\ Ecole d'Ingénieurs de Genève (EIG) \\ Institute of Fabrication Processes, Materials and Fluid Mechanics (IMEC) \\ CH 1213 Petit-Lancy, Switzerland,
}

\begin{abstract}
A PCM dephaser and storage module based on a melting/freezing model was built and implemented into the Dymola-Modelica software. This software offers thermal libraries with standard components as tubes, pumps, heat exchangers, etc. Main simulation results of interest include the phase shift (delay time) caused by cylinders filled with a PCM and positioned in the storage/dephasing device. Furthermore, an entire Minergie $^{\mathrm{TM}}$ house was modelled by a rather simple (economic in terms of CPU time), but still very effective thermal model. This house is connected to a suitable ventilation system chosen from a list of six different types. Therefore, also by graphical means on an interface, it is possible to create a Minergie ${ }^{\mathrm{TM}}$ house with an integrated thermal temperature lowering/phase shifting and heat recovery device. Temperature differences between a Minergie ${ }^{\mathrm{TM}}$ house connected to a storage device and a house without such a device are studied. Such systems are planned to be mainly used for hybrid cooling of Swiss Minergie ${ }^{\mathrm{TM}}$ houses in summer time. In a multi-functional application, they could also be applied in winter for a heating support. Numerous simulation results are discussed and optimal solutions are presented.
\end{abstract}

\section{INTRODUCTION}

PCM storage tanks have been studied for many years. A comprehensive overview has been written by Lane (1986). Hed and Bellander (2006) have developed a mathematical model of a PCM-air heat exchanger without taking into account the temperature distribution in the PCM. Butala and Stritiht (2006) have shown that it is possible to flatten a temperature curve with a PCM storage tank connected to a simple ventilation system. Finally, Turnpenny, Etheridge and Reay (1999) have shown that they get $30 \mathrm{~W} \mathrm{~m}^{-2}$ for an office building by having a forced air flow in each $15 \mathrm{~m}^{2}$ office. Haas and Temporin (2007) have studied the aerodynamics of a thermal wave dephasing device with sensible heat storage. The outside air temperature has a daily profile close to a sinusoidal function; therefore it is possible - with 12 hours of dephasing - to get a minimal temperature from the dephasing device while the outside air temperature is at its maximum. With such a system it is possible to cool down a house by taking the outside air during the night, whereas during the day the air coming out of the dephasing device is used. In their paper they have shown that it is possible to get 12 hours of dephasing with a $0.9 \mathrm{~m}$ long dephasing device performed of copper and filled with water. They also found that with these materials the transmission stays above $85 \%$. In this paper the idea of a dephasing device with phase change materials is studied. But the use of a PCM as a storage substance is also of interest and dealt with. Furthermore, a house model is built to compare the interior air temperatures of houses with and without a PCM storage device. The reference house is a villa for four people with $164 \mathrm{~m}^{2}$ surface of energy reference (SRE). The SRE is the total surface with the walls and with a height factor for taking into account different floors. To get the Swiss Minergie ${ }^{\mathrm{TM}}$ label for a new house, the walls must be insulated so that the annual consumption of energy for heating is less than $38 \mathrm{kWh} / \mathrm{m}^{2}$. That means that the annual consumption of the total house is less than $7600 \mathrm{kWh} /$ year. The power for cooling has to be smaller than 7 $\mathrm{W} / \mathrm{m}^{2}$. This corresponds to a total cooling power smaller than $1150 \mathrm{~W}$. This cooling power is not sufficient to cover the occurring loads. Therefore, it is advisable to additionally install a "free cooling" device to condition fresh air during temperate, but specially on hot summer days. 


\section{PHYSICAL MODEL}

A device with cylindrical Phase Change Material (PCM) modules is modeled by the Continuous-Properties Model (CPM) introduced by Egolf and Manz (1994). It is necessary to apply numerical methods, because of the analytical insolvability of the nonlinear second order partial differential equation. For the bulk in the PCM cylinders, the basic differential equation in cylindrical coordinates is:

$$
\frac{\partial T}{\partial t}=\alpha\left[\frac{1}{k} \frac{d k}{d T}\left(\frac{\partial T}{\partial r}\right)^{2}+\frac{1}{r} \frac{\partial T}{\partial r}+\frac{\partial^{2} T}{\partial r^{2}}\right], \quad \alpha=\frac{k}{\rho c_{p}}
$$

By energy conservation, the basic differential equation for the heat flux at the inner surface of the cylinders is:

$$
-k \frac{\partial T}{\partial r}=h\left[T(R)-T_{F}\right]
$$

On the other hand only an algebraic equation occurs to describe the outer boundary condition:

$$
\dot{m}_{F} \quad c_{p_{F}}\left(T_{F_{\text {out }}}-T_{F_{\text {in }}}\right)=h A\left[T(R)-T_{F_{\text {in }}}\right]
$$

In Euler's method the derivatives are replaced by the difference quotients. The index $i$ defines the discrete time and $j$ the discrete radial position. A development of the model of a device has been performed by Muriset et al. (2009). The numerical algorithms are the following:

$$
\begin{gathered}
T_{i+1, j}=T_{i, j}+\frac{\alpha \Delta t}{(\Delta r)^{2}}\left[\left.\frac{1}{k_{i, j}} \frac{d k}{d T}\right|_{i, j}\left(T_{i, j+1}-T_{i, j}\right)^{2}+\frac{\Delta r}{r_{j}}\left(T_{i, j+1}-T_{i, j}\right)+\left(T_{i, j+1}-2 T_{i, j}+T_{i, j-1}\right)\right] \\
T_{i, n}=\frac{T_{i, n-1}+B i T_{F_{i n}}}{1+B i} \quad \text { whereas } \quad B i=\frac{h \Delta r}{k_{i, n}} \\
T_{F_{\text {out }}}=T_{F_{\text {in }}}+S t\left(T_{i, n}-T_{F_{\text {in }}}\right) \quad \text { whereas } \quad S t=\frac{h A}{\dot{m}_{F} c_{p_{F}}}
\end{gathered}
$$

\section{PCM PROPERTIES}

The enthalpy, specific heat and thermal conductivity in the CPM are functions of the temperature and are each described by two exponential equations. Some are for temperatures lower than the mean temperature of a mushy phase change domain, and the others are developed to describe physical properties in the higher temperature regime. The chosen PCM is the ClimSel 21-22 with the physical properties shown in table 1.

Table 1 : Properties of the ClimSel 21-22 PCM are listed. For simulations of systems with other melting temperatures than $21.5^{\circ} \mathrm{C}$, except of the melting temperature, all parameters are the same as in Table 1.

\begin{tabular}{|l|l|r|l|}
\hline$k_{1}$ & Thermal conductivity for PCM in solid phase (for $T \rightarrow 0)$ & 0.5 & $\mathrm{~W} \mathrm{~m}^{-1} \mathrm{~K}^{-1}$ \\
\hline$k_{2}$ & Thermal conductivity for PCM in liquid phase (for $T \rightarrow \infty)$ & 0.7 & $\mathrm{~W} \mathrm{~m}^{-1} \mathrm{~K}^{-1}$ \\
\hline$c_{p 1}$ & Specific heat for PCM in solid phase (for $T \rightarrow 0$ ) & 3600 & $\mathrm{~J} \mathrm{~kg}^{-1} \mathrm{~K}^{-1}$ \\
\hline$c_{p 2}$ & Specific heat for PCM in liquid phase (for $T \rightarrow \infty)$ & 3600 & $\mathrm{~J} \mathrm{~kg}^{-1} \mathrm{~K}^{-1}$ \\
\hline$h_{2}-h_{1}$ & Projected latent heat of liquefaction & 144 \\
\hline$\rho$ & Density & 1450 & $\mathrm{~J} \mathrm{~kg} \mathrm{k}^{-1}$ \\
\hline$T_{m}$ & Average melting temperature & 21.5 & ${ }^{\circ} \mathrm{C}^{-3}$ \\
\hline$\Delta T$ & Width of mushy region & 1 & ${ }^{\circ} \mathrm{C}$ \\
\hline
\end{tabular}




\section{DEPHASING RESPONSE}

In a report by Muriset et al. (2009) the system parameters for a dephasing device have been optimised. The geometrical parameters are explained in Figure 1.

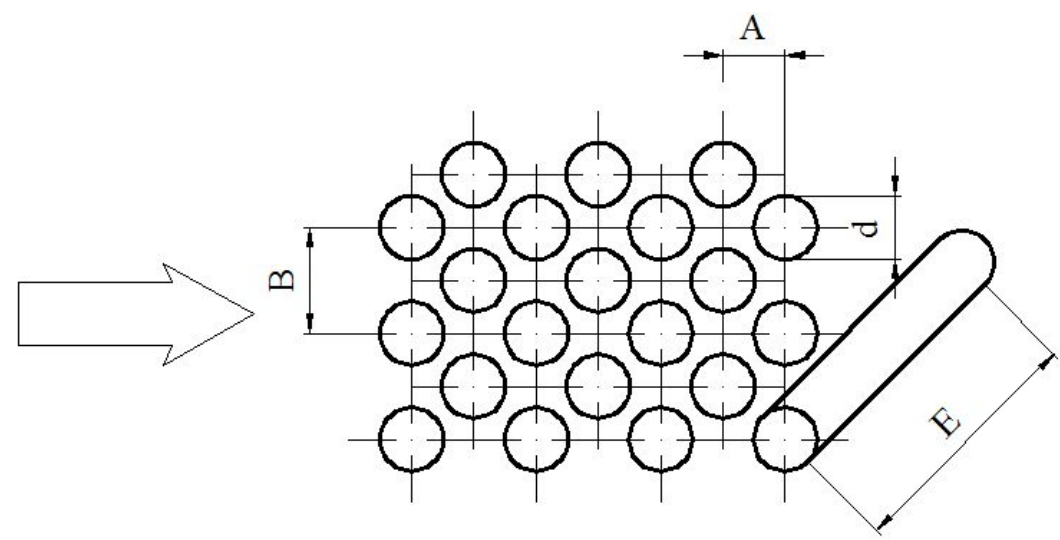

Figure 1: Geometrical dimensions of a storage tank are defined in the drawing on the lefthand side. Here $d=2 \mathrm{~cm}, B=1.5$ $d, A=1 d$ and $v=0.5 \mathrm{~m} \mathrm{~s}^{-1}$ between two vertical cylinders. Staggered cylinders lead to the best results concerning heat exchange. The flow is perpendicular to the cylinder axes and no azimuthal temperature dependence is taken into consideration.

For a dephasing device two aspects are important. The first is the dephasing itself, which is the difference of time between a maximum of the air temperature at the exit and a maximum at the entry of the dephasing device. The second important quantity is the ratio of the temperature amplitudes of the air at the exit and the inlet. Simulations have been performed for a storage device that has ten columns of cylinders, which lead to a $20 \mathrm{~cm}$ long storage device.

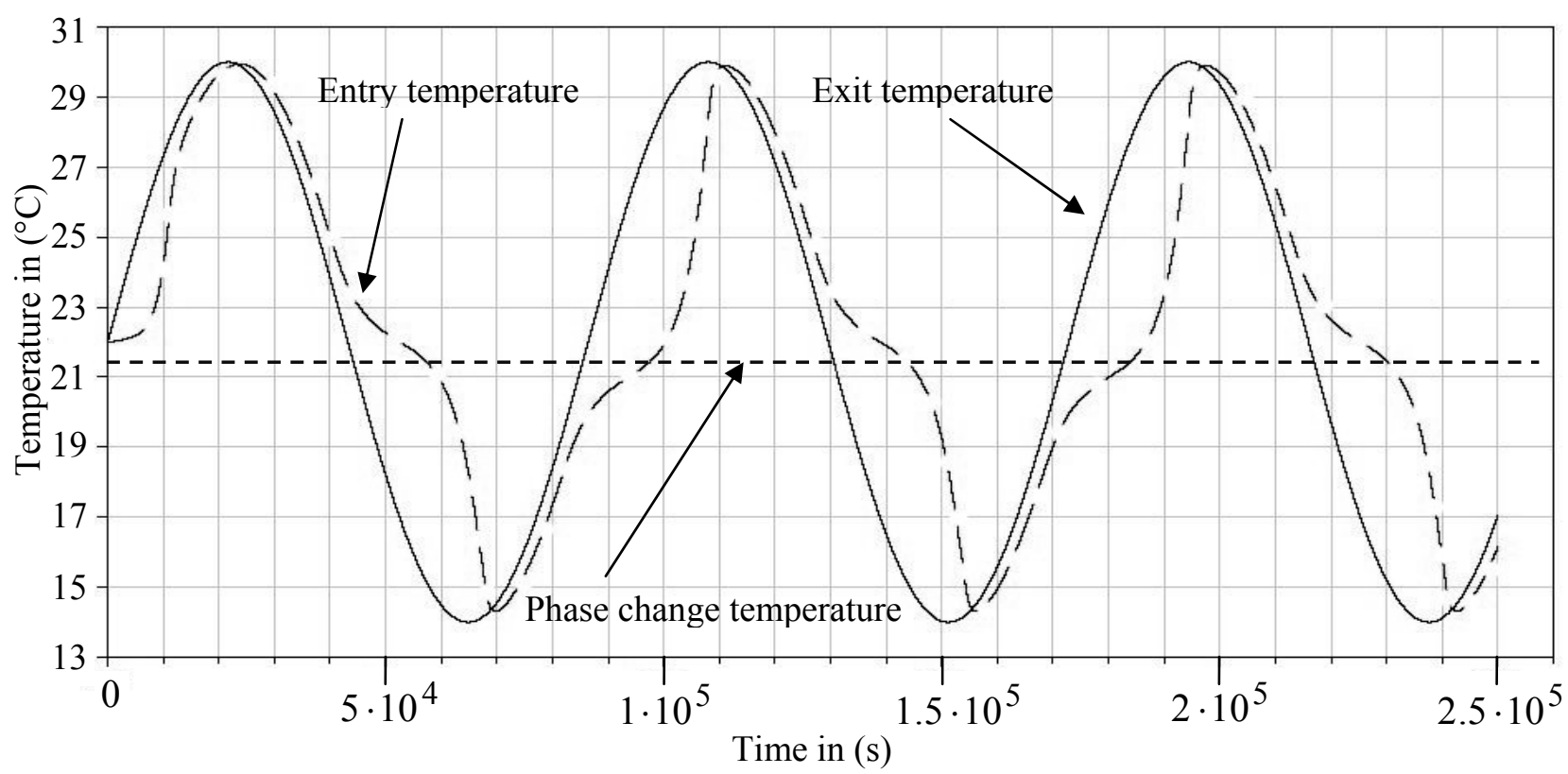

Figure 2: Entrance (inlet) and exit (outlet) temperatures of a storage tank with ten cylinders.

In Figure 2 it is seen that the dephasing occurring at the maximal temperature is not the same as at the minimal temperature. It also shows an asymmetry of the transmission. The transmission for the maximal temperature is larger than for the minimal one. Figure 2 shows that the PCM creates an expected flatness of the temperature profile in the mushy region domain of the PCM. With thirty cylinders the flatness extends from one day to a next one. So the exit temperature is nearly constant. These characteristics show that the use of a PCM for a dephasing device is not quite accurate. Therefore, it is more adapted to use a PCM storage tank directly for energy storage. To investigate on a realistic behaviour of storage tank efficiency, it is required to also refer to a physical model of a house. With such a model it is possible to compare the inside temperature of the house having a storage tank with the temperature of one without. 


\section{MODEL OF A MINERGIETM HOUSE}

A physical model of a house has been applied by referring to an existing model, developed by Burmeister and Keller (1998). This model is rather simple (economic in term of CPU time) but still efficient and quite accurate concerning the interior temperature of a defined house as a function of time:

$$
T_{i}(t)=-\frac{C}{K} \frac{d T_{i}(t)}{d t}+T_{e}(t)+\frac{1}{K} P_{i}(t)+\frac{1}{K} P_{\text {heat } / \text { cool }}(t)
$$

with:

$$
P_{\text {heat } / \text { cool }}=\frac{\dot{m}_{\text {air }} c_{p_{\text {air }}}\left(T_{\text {puls }}-T_{i}\right)}{S_{\text {tot }}} \quad \text { and } \quad K=\frac{\sum_{i} A_{i} U_{i}}{\sum_{i} A_{i}}
$$

Figure 3 shows different occurring powers taken from the Swiss standards SIA V382/2.

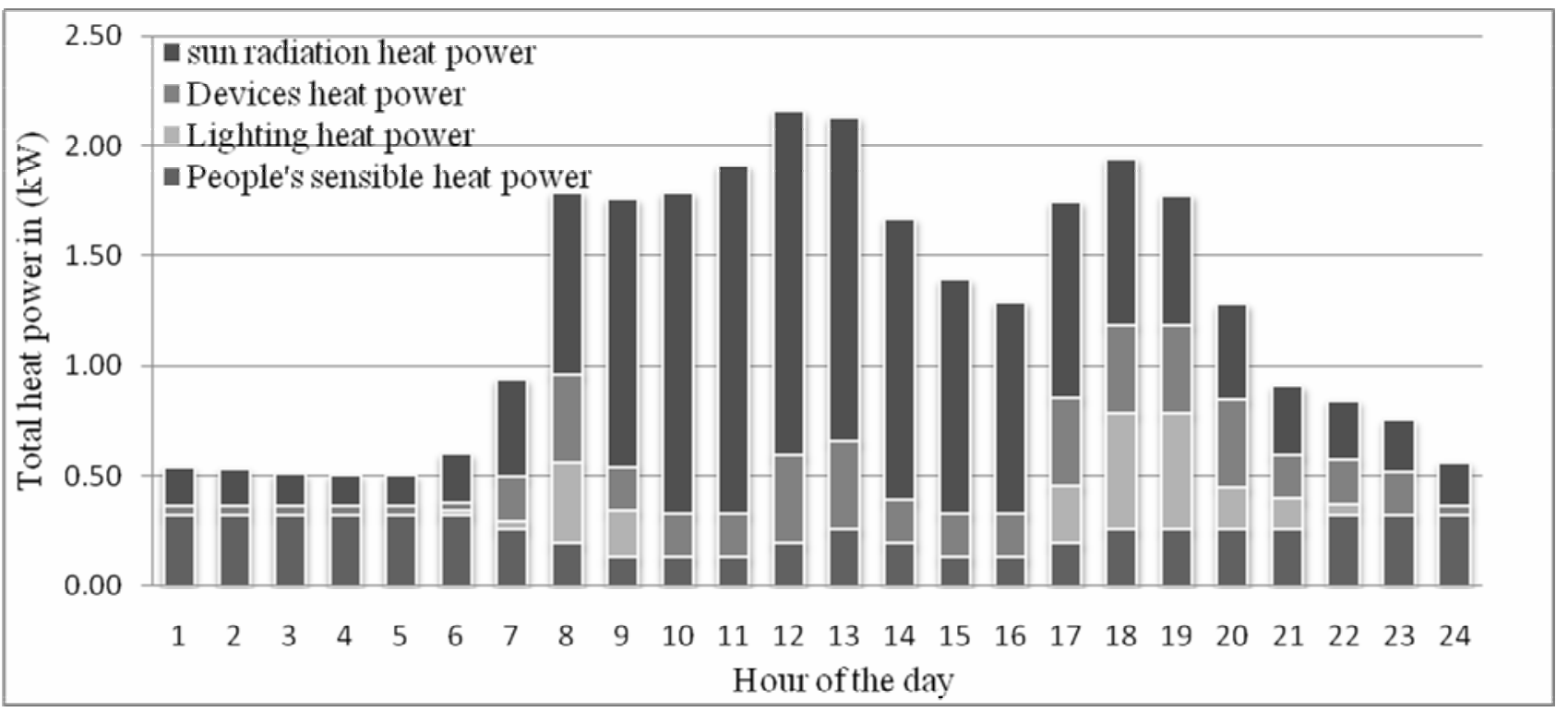

Figure 3: Heat power of people, lighting, household devices and solar radiation taken as input parameters for the applied house model.

The house was given the following specifications:

$K=0.294 \mathrm{~W} \mathrm{~m}^{-2} \mathrm{~K}^{-1}$

$C=169^{\prime} 679 \mathrm{~J} \mathrm{~m}^{-2} \mathrm{~K}^{-1}$

$m_{s}=448 \mathrm{~kg} \mathrm{~m}^{-2}$

$K$ is the mean heat transfer coefficient; $C$ is the thermal capacity of the building divided by the surface of the external walls, $m_{s}$ is the mass of the walls divided by the surface of the house. The high value of $C$ indicates that the domestic house shows a heavy building style.

\section{THE AIR-CONDITIONING SYSTEM}

The air conditioning system is composed of a heat recovery bypass, a storage tank bypass and an independent ventilation system to allow a larger air flux going through it during the night. During the day the air goes through the heat recovery device and the storage tank where it is cooled. Fresh air is finally brought into the house. During the night the independent ventilation for the storage tank is turned on to cool the storage device with an air flux of $2000 \mathrm{~m}^{3} \mathrm{~h}^{-1}$. At the same time the house is ventilated with outside air. Air flowing into the house has always a volume flow of $500 \mathrm{~m}^{3} \mathrm{~h}^{-1}$. This air flux allows good hygienic conditions and also has sufficient cooling capacity. Even if this system is expensive, it has been chosen from six different candidates (see Muriset et al., 2008), because it is the most advantageous concerning an effective cooling of energy gains. A schematic drawing of this system is shown in figure 4. 


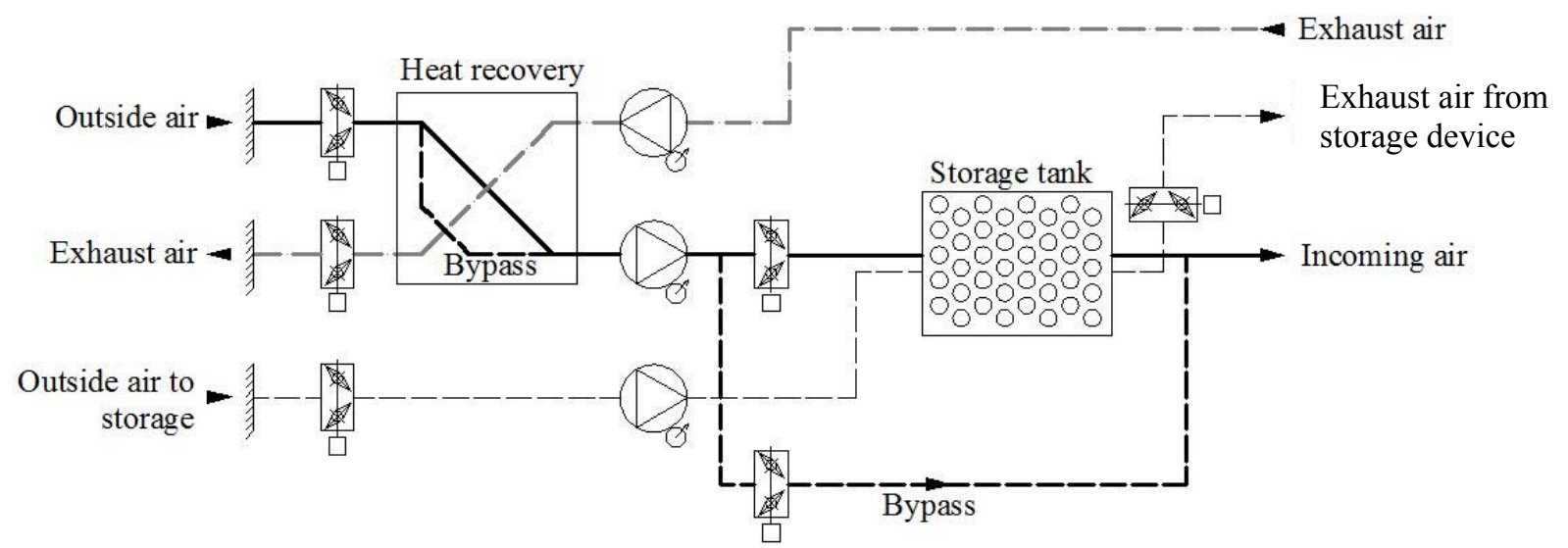

Figure 4: The air-conditioning system has as main components a heat recovery and a storage device.

\section{RESULTS OBTAINED WITH THE HOUSE MODEL}

The solutions shown in this chapter were obtained with the outside temperature taken from the Design Reference Year DRY. This data set contains hourly data of the outside temperature, humidity, solar global radiation and cloud covering degree. It is specially prepared for numerical simulations and takes into account the peaks of temperature during summer, but also during periods of cold. For the following simulation, the location was chosen to be Geneva. The five days taken from DRY are the hottest of the year. The storage device has fourty columns of cylinders which add up to a storage device of $80 \mathrm{~cm}$ lenght.

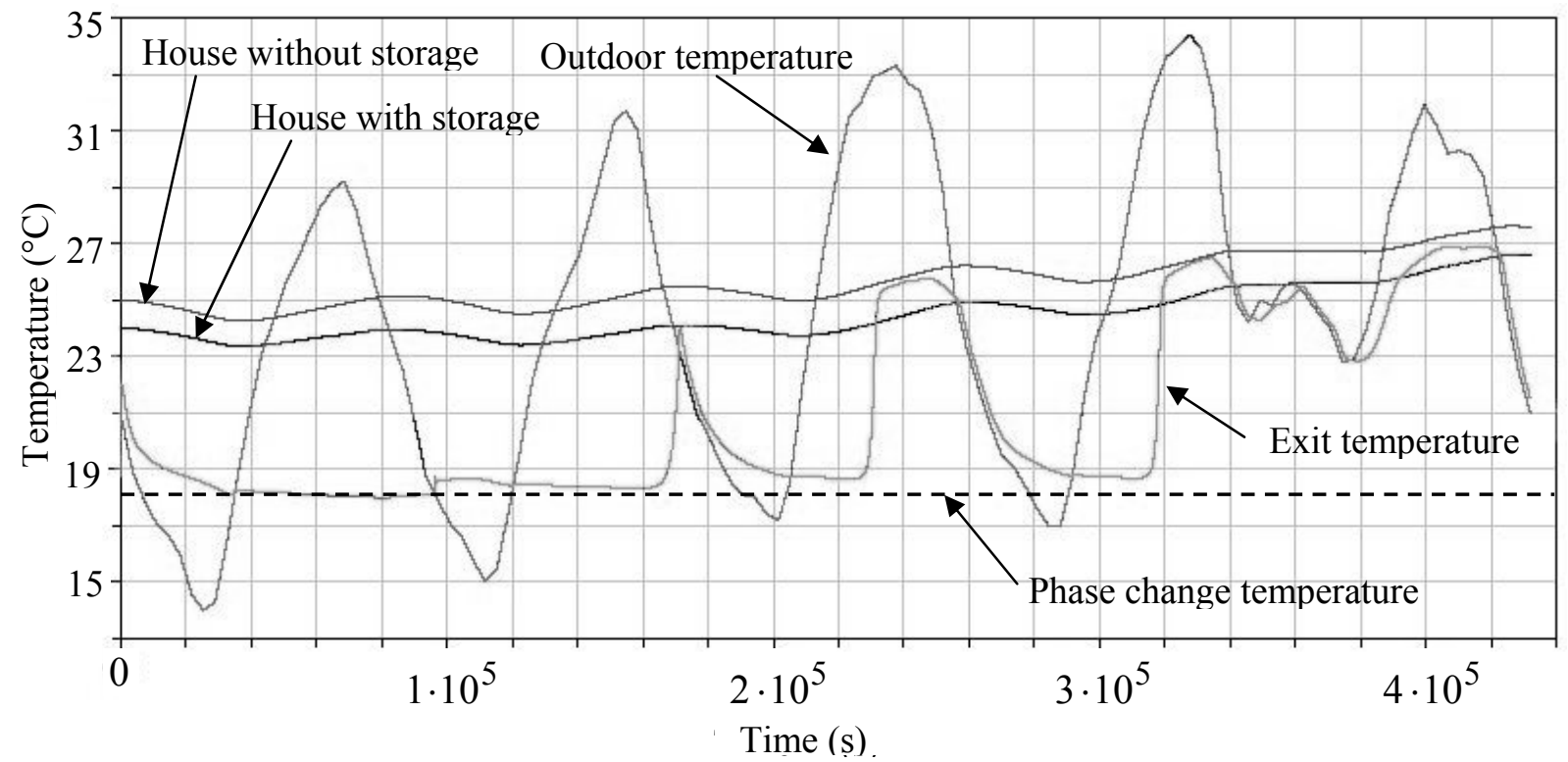

Figure 5: Comparison of temperatures of a modelled house with and without a storage tank are presented.

\section{DISCUSSION OF RESULTS}

Figure 5 shows that the temperature of the exit of the storage stays very low for the first two days. It means that the PCM is in its solid state in this period. During the third and the fourth day the PCM liquefies while the outside temperature is high. The outside temperature at night between the forth and the fifth day has a minimum, which is five Kelvin higher than the mean melting temperature of the PCM. Therefore, the storage tank has no chance to solidify under these conditions. But days with such temperatures are very rare and do not have a large effect on the temperature in the interior of the house. Figure 5 shows that the temperature in the house linked to such a storage tank is up to $1.4 \mathrm{~K}$ lower than the temperature in the same house without a storage tank. The initial difference between the temperatures in the two house configurations is $1 \mathrm{~K}$. This difference increases during the three first and reduces during the last two days. This means that 
if a temperature profile - as obtained for the three first days - would last for one week, then the cooling effect would be larger. The house has a large heat capacity, and it is therefore considered to have a heavy building style. A simulation for a light one - which has a heat capacity of only $65 \mathrm{~kJ} \mathrm{~m}^{-2} \mathrm{~K}^{-1}$ - shows that the difference of temperature between the house with and without a storage tank after two days will be $2.2 \mathrm{~K}$. To avoid that the PCM melts too early during the day, an efficient method is to choose a PCM with a higher melting temperature. But as the cooling power is directly proportional to the difference of the temperature span between the temperature in the house and the one of the incoming air, the cooling power would decrease for most of the days. The applied simulation parameters are listed in table 2.

\section{PARAMETER LISTING}

Table 2: The geometrical and physical properties of the phase change material storage are listed below.

\begin{tabular}{|c|c|c|c|}
\hline Symbols & Definition & value & unit \\
\hline$A$ & Distance between two cylinders in the air flow direction & 0.02 & $\mathrm{~m}$ \\
\hline$B$ & Distance between two cylinders perpendicular to the air flow direction & 0.03 & $\mathrm{~m}$ \\
\hline$C$ & Specific heat capacity of the house & $169^{\prime} 679$ & $\mathrm{~J} \mathrm{~m}^{-2} \mathrm{~K}^{-1}$ \\
\hline$C_{1}$ & Proportionality factor in the Nusselt number & 0.497 & - \\
\hline$c_{p}$ & Specific heat of air & 1004 & $\mathrm{~J} \mathrm{~kg}^{-1} \mathrm{~K}^{-1}$ \\
\hline$c_{p 1}$ & Specific heat of PCM in solid phase (for $T \rightarrow 0$ ) & 3600 & $\mathrm{~J} \mathrm{~kg}^{-1} \mathrm{~K}^{-1}$ \\
\hline$c_{p 2}$ & Specific heat of PCM in liquid phase (for $T \rightarrow \infty$ ) & 3600 & $\mathrm{~J} \mathrm{~kg}^{-1} \mathrm{~K}^{-1}$ \\
\hline$d$ & Diameter of the cylinders & 0.02 & $\mathrm{~m}$ \\
\hline$E$ & Length of the cylinders (chapter 7) & 13.8 & $\mathrm{~m}$ \\
\hline$h$ & Convective heat transfer coefficient & $\mathrm{f}\left(v_{\max }\right)$ & $\mathrm{W} \mathrm{m^{-2 } \mathrm { K } ^ { - 1 }}$ \\
\hline$h_{2}-h_{1}$ & Latent heat of solidification & 144000 & $\mathrm{~J} \mathrm{~kg}^{-1}$ \\
\hline$K$ & Mean heat transfer coefficient & 0.294 & $\mathrm{~W} \mathrm{m^{-2 } \mathrm { K } ^ { - 1 }}$ \\
\hline$k_{1}$ & Thermal conductivity of PCM in solid phase (for $T \rightarrow 0$ ) & 0.5 & $\mathrm{~W} \mathrm{~m}^{-1} \mathrm{~K}^{-1}$ \\
\hline$k_{2}$ & Thermal conductivity of PCM in liquid phase (for $T \rightarrow \infty$ ) & 0.7 & $\mathrm{~W} \mathrm{~m}^{-1} \mathrm{~K}^{-1}$ \\
\hline $\mathrm{m}$ & Factor in Nusselt relation & 0.558 & - \\
\hline$m_{s}$ & Specific mass of the building & 448 & $\mathrm{~kg} \mathrm{~m}^{-2}$ \\
\hline$n$ & Number of radial elements & 20 & - \\
\hline$N_{1}$ & Number of cylinders (chapter 4 ) & 10 & - \\
\hline$N_{2}$ & Number of cylinders (chapter 7) & 40 & - \\
\hline$t_{f 1}$ & Final time of simulation (chapter 4) & $259 ’ 200$ & $\mathrm{~S}$ \\
\hline$t_{f 2}$ & Final time of simulation (chapter 7) & $432 ’ 000$ & $\mathrm{~S}$ \\
\hline$t_{\text {ini }}$ & Starting time of the simulations & 0 & $\mathrm{~s}$ \\
\hline$T_{m 1}$ & Average phase change temperature (chapter 4 ) & 21.5 & ${ }^{\circ} \mathrm{C}$ \\
\hline$T_{m 2}$ & Average phase change temperature (chapter 7) & 18 & ${ }^{\circ} \mathrm{C}$ \\
\hline$T_{i n i}$ & Initial temperature of the PCM cylinders & 22 & \\
\hline$T_{i 1}$ & Initial temperature of the house connected to the storage device & 24 & ${ }^{\circ} \mathrm{C}$ \\
\hline$T_{i 2}$ & Initial temperature of the house not connected to the storage device & 25 & ${ }^{\circ} \mathrm{C}$ \\
\hline$v_{1}$ & Air speed between two vertical cylinders for $500 \mathrm{~m}^{3} \mathrm{~h}^{-1}$ (chapter 4) & 0.6 & $\mathrm{~m} \mathrm{~s}^{-1}$ \\
\hline$v_{\max I}$ & Maximal air speed in the storage device for $500 \mathrm{~m}^{3} \mathrm{~h}^{-1}$ (chapter 4) & 1.2 & $\mathrm{~m} \mathrm{~s}^{-1}$ \\
\hline$v_{2}$ & Air speed between two vertical cylinders for $500 \mathrm{~m}^{3} \mathrm{~h}^{-1}$ (chapter 7) & 1 & $\mathrm{~m} \mathrm{~s}^{-1}$ \\
\hline$v_{\max 2}$ & Maximal air speed in the storage device for $500 \mathrm{~m}^{3} \mathrm{~h}^{-1}$ (chapter 7) & 2 & $\mathrm{~m} \mathrm{~s}^{-1}$ \\
\hline$\dot{V}$ & Volume flow (chapter 7) & 0.138 & $\mathrm{~m}^{3} \mathrm{~s}^{-1}$ \\
\hline$\Delta t$ & Time increment & 0.1 & $\mathrm{~s}$ \\
\hline$\rho$ & Specific mass & 1450 & $\mathrm{~kg} \mathrm{~m}^{-3}$ \\
\hline$\tau_{1}$ & Phase change range (for $\mathrm{T}<\mathrm{T}_{\mathrm{m}}$ ) & 0.5 & $\mathrm{~K}$ \\
\hline$\tau_{2}$ & Phase change range (for $\mathrm{T}>\mathrm{T}_{\mathrm{m}}$ ) & 0.5 & $\mathrm{~K}$ \\
\hline
\end{tabular}




\section{CONCLUSION AND OUTLOOK}

This study shows that for the defined case of a Minergie ${ }^{\mathrm{TM}}$ house a good PCM storage device consists of cylinders with a diameter of two centimetres, staggered with a small distance between the cylinders in the flow direction. This geometry allows all the PCM to change its phase in a single cycle, and these parameters also lead to an ideal heat exchange. For a cooling of a house in Geneva, the best melting temperature has been determined to be approximately $18^{\circ} \mathrm{C}$. The losses of cooling power during the three days in which the lowest temperature is even higher than $18{ }^{\circ} \mathrm{C}$ are extensively overwhelmed by the gains of neighbouring days. The proposed storage device permits to refresh a house by $1.4 \mathrm{~K}$ for a heavy and $2.2 \mathrm{~K}$ for a light type of building with a very small amount of auxiliary energy to drive the system (ventilators, etc.). That naturally leads to a very high coefficient of performance (COP). The electric consumption peak of such systems occurs during the night and not during the day as for conventional cooling systems. This means that on one hand the general peak of energy consumption is reduced and on the other hand the price for the consumed electricity is lower. It is assumed that as long as energy will concern us, and that the energy laws will become more and more restrictive, technical systems with PCM's will be moving more and more into the focus of public interest.

\section{ACKNOWLEDGEMENTS}

The authors are grateful to the Hesso funding agency for its support. The first three authors thank Patrick Haas for demanding their participation in the Hesso project "Déphaseur". They also thank Robert Weber (EMPA, Dübendorf, Switzerland) for helpful actions to maintain some activities in this important domain, e.g. a participation in an EU cost action.

\section{NOMENCLATURE}

\section{Standard}

$\begin{array}{ll}A & \text { Surface } \\ c & \text { Specific heat (for liquids or solids) } \\ c_{p} & \text { Specific heat at constant pressure (for a gas) } \\ h & \text { Heat transfer coefficient } \\ h & \text { Specific enthalpy } \\ i & \text { Index time } \\ j & \text { Index space } \\ k & \text { Thermal conductivity } \\ l & \text { Width of the plates } \\ L_{f} & \text { Specific heat of liquefaction (latent heat) } \\ \dot{m} & \text { Mass flow } \\ P & \text { Specific heat flux } \\ r, \varphi, z & \text { Cylindrical coordinates } \\ T & \text { Temperature } \\ t & \text { Time } \\ v & \text { Velocity } \\ x, y, z & \text { Cartesians coordinates }\end{array}$

$\mathrm{m}^{2}$
$\mathrm{~J} \mathrm{~kg}^{-1} \mathrm{~K}^{-1}$
$\mathrm{~J} \mathrm{~kg}^{-1} \mathrm{~K}^{-1}$
$\mathrm{~W} \mathrm{~m}^{-2} \mathrm{~K}^{-1}$
$\mathrm{~J} \mathrm{~kg}^{-1}$
-
-
$\mathrm{W} \mathrm{m} \mathrm{K}^{-1}$
$\mathrm{~m}$
$\mathrm{~J} \mathrm{~kg}^{-1}$
$\mathrm{~kg} \mathrm{~s}^{-1}$
$\mathrm{~W} \mathrm{~m}$
$\mathrm{~m},-, \mathrm{m}^{-3}$
$\mathrm{~K}$
$\mathrm{~s}$
$\mathrm{~m} \mathrm{~s}$
$\mathrm{~m}$

\section{Nondimensional numbers}

$\begin{array}{ll}B i & \text { Biot number } \\ \text { St } & \text { Stanton number }\end{array}$

\section{Greek}

$\begin{array}{lll}\alpha & \text { Diffusivity } & \mathrm{m}^{2} \mathrm{~s}^{-1} \\ \Delta & \text { Difference } & - \\ \theta & \text { Temperature difference between fluid and solid } & \mathrm{K} \\ \rho & \text { Density } & \mathrm{kg} \mathrm{m}^{-3}\end{array}$




$\begin{array}{ll}\text { Indices } & \\ F & \text { Fluid } \\ \text { in } & \text { Inlet } \\ \text { out } & \text { Outlet }\end{array}$

\section{REFERENCES}

1. Burmeister H., Keller B., 1998, Climate surface: a quantitative building-specific representation of climates, Energy and Buildings , 28(2): 167-177.

2. Butala V., Stritiht U., 2006, Cold storage with phase change material for building ventilation, Int.J. Ventil. 5(2): 189-198.

3. Egolf P.W., Manz H., 1994, Theory and modelling of phase change materials with and without mushy regions, Int. J. Heat Mass Transfer 37(18): 2917-2924.

4. Haas P., Temporin P., 2007, Etude aérodynamique d'un déphaseur d'ondes thermiques. Final report of a Hesso project, Sagex No. 17239.

5. Hed G., Bellander R., 2006, Mathematical modelling of PCM air heat exchanger, Energy and Buildings, 38(2): 82-89.

6. Lane G.A., 1986, Solar heat storage: Latent heat material, Volume I and II, CRC Press, Florida.

7. Muriset C., Egolf P.W., Vuarnoz D., 2008, Stock d'Energie Thermique par Matériel à Changement de Phase, internal report, Hes-so Sagex No. 17'239.

8. Turnpenny J.R., Etheridge D.W., Reay D.A., 1999, Novel ventilation cooling system for reducing air conditioning in building, Part I, Applied Thermal Engeneering 20(11): 1019-1037.

9. Internet: http://www.climator.com/. 